\title{
DERECHO PRIVADO
}

La contradición evidente en el concepto moderno de gobierno, según el cual la única cosa que los individuos tienen en común es el interés privado, no es problemática para nosotros como lo era para Marx, porque sabemos que la contradicción entre privado y público, típica de los estadios iniciales de la edad moderna, ha sido un fenómeno temporario que cedió a una extinción total de la diferencia entre esfera privada y esfera pública, y a la absorción de ambas en la esfera social. Por ese motivo, estamos en una posición mucho más adecuada para comprender las consecuencias, para la existencia humana, de la desaparición de las esferas distintas de vida pública y privada, habiendo llegado a ser lo público función de lo privado y habiendo llegado a ser lo privado el único interés común que ha quedado en pie.

Hannah Arendt, Vita activa. La condición humana, cap. II

La sorpresa como fenómeno jurídico en la legislación europea: formación y efectos

Fernando Gandini 



\title{
La sorpresa como fenómeno jurídico en la legislación europea: formación y efectos
}

\begin{abstract}
Fernando Gandini
Current techniques in communication and negotiation have had a direct influence on those of formation, execution and conclusion of contracts. This work intends to formulate some normative effects which this situation has generated in European law contracts and analyzes the manner in which such effects contribute to the development of traditional juridical figures.
\end{abstract}

\section{El punto de partida: la disciplina de los contratos del consumidor}

Por contratos del consumidor se entiende:

[...] categoría variada de contratos, en los cuales una de las partes es el consumidor; el énfasis recae en el consumidor mismo, para subrayar que ésta es la parte sobre la que el legislador hace particular referencia al dictar una norma: una parte considerada más débil respecto a la contraparte que debe, por consiguiente, ser protegida. Estos contratos, no están destinados a regular las relaciones entre consumidores, sino las relaciones que el consumidor entabla con profesionales. ${ }^{1}$

Esta disciplina contractual, encontró sus primeros antecedentes en la Comunidad Económica Europea durante la mitad de los años setenta con un proyecto normativo que intentaba garantizar mayor información y transparencia a lo largo del proceso negocial, tuvo posteriormente un desarrollo independiente en países como Alemania y Francia relacionado con la regulación de los contratos

${ }^{1}$ Alpa Giudo, Istituizioni di diritto privatto, página 612, Editorial Giappichelli, Torino. Novena Edición. 
celebrados a través de formularios y, finalmente, en la década de los noventa, alcanzó su verdadera dimensión con la regulación comunitaria de temas tan variados como los contratos celebrados fuera de establecimiento mercantil, los contratos celebrados a distancia, los contratos de crédito de consumo, los contratos de viaje y los contratos de adquisición de bienes y servicios.

Ha sido la disciplina de contratos del consumidor -que se produce como respuesta a las necesidades que crean las relaciones que una persona, el consumidor, entabla no solo con los empresarios y productores, sino también con novedosas técnicas de venta y de negociación que modifican considerablemente su posición tradicional dentro de la relación contractual, trayéndole una serie significativa de riesgos- la que ha permitido la gestación de la sorpresa como fenómeno con alcances jurídicos, así esta no sea tratada en ningún cuerpo normativo de manera específica.

La figura del consumidor, que puede entenderse como la persona física que actúa con objetivos diversos a la actividad empresarial o profesional que usualmente desarrolla, y que tiene interpretaciones más amplias que indican que es consumidor "también aquel profesional o empresario para el cual la conclusión del contrato no significa un desarrollo de su profesión como lo es para su contraparte", ${ }^{2}$ adquiere mayor importancia cuando se piensa que la tutela de sus derechos, no se limita al individuo como tal, sino que se expande hasta constituir un sistema de protección en masa para una categoría determinada de participantes de las relaciones económicas. En este punto, resulta determinante hacer énfasis en que si bien la política de protección al consumidor tiene una enorme importancia dentro de las relaciones jurídico-contractuales de la actualidad, no puede entenderse como un fin en si misma, ya que no agota su concepción por si sola. La protección al consumidor es un medio idóneo para lograr una eficiente protección del mercado, que requiere de operaciones económicas sanas, en donde las partes intervinientes no vean vulnerados sus intereses, y mucho menos sus derechos. Un consumidor bien protegido legislativamente, está en capacidad de celebrar un contrato y de finalizar su ejecución con resultados económicos y jurídicos positivos, que le permiten estar en condiciones de celebrar nuevas operaciones contractuales.

\section{Concepto de sorpresa}

A nivel jurídico contractual la sorpresa se entiende como "un acontecimiento inesperado, producto ya sea del medio, forma o técnica de contratación, así como del inadecuado funcionamiento de un sistema normativo, que provoca

${ }^{2}$ Giurisprudenza. Tribunale Roma, 20 Ottobre 1999 
en las partes o en alguna de ellas, la limitación o la distorsión de la capacidad de querer o de entender". ${ }^{3}$

La anterior definición, es susceptible de ser dividida en tres partes y a su vez estas, pueden ser analizadas individualmente: a) es fundamentalmente un acontecimiento inesperado, una situación que no es posible prever por una de las partes inmersa en el proceso contractual, el consumidor, que no espera encontrarse frente a un proceso de negociación y contratación; b) el acontecimiento inesperado es producido generalmente por los medios, formas o técnicas de contratación utilizados por el vendedor. Esto quiere decir que el operador económico, quien en realidad tiene la iniciativa negocial, se vale de una serie de estrategias para incluir a un consumidor, inicialmente pasivo, en su proceso contractual para convencerlo de que celebre el contrato; c) la situación creada por el vendedor con dichos medios, formas o sistemas de venta trae tal presión y confusión en el consumidor, que genera una limitación o distorsión en su capacidad de querer o de entender. Esto, tiene una influencia directa dentro del proceso de formación del contrato: la voluntad de uno de los contrayentes, como elemento determinante para la formación del consentimiento y por ende para la existencia del contrato se ve afectada de tal manera que el consumidor: 1) no entiende la situación en la que está entrando, 2) no es consciente de las consecuencias o efectos que esa relación trae consigo, 3) en realidad no desea celebrar el contrato que en últimas está celebrando.

Para obtener un ejemplo práctico y significativo de la manifestación de la sorpresa en una situación cotidiana, se debe reiterar una situación ya enunciada anteriormente: el fenómeno de la sorpresa no es tratado de manera directa en ninguna norma en particular, se debe identificar en la política de protección al consumidor a través de los diferentes tipos contractuales que la conforman. De esta manera, es posible intentar una categorización del fenómeno a la luz de una diversidad de contratos.

El primer ejemplo está contextualizado por la directiva 85/577/CE 4 que regula el tema de los contratos celebrados fuera de establecimiento de comercio

\footnotetext{
${ }^{3}$ Gandini Fernando. Tesis de maestría. "La sorpresa nei contratti negoziati fuori dei locali commerciali - Comparazione com altre fattispecie” Università Roma Tre 2004.

${ }^{4}$ De acuerdo con los tratados de Roma, una directiva es una decisión colectiva mutuamente obligatoria aprobada por los Estados Miembros de la Unión Europea. Obliga a todos o parte de los Estados miembros en cuanto al objetivo a alcanzar, pero les permite elegir la forma y los medios para conseguir tales objetivos.
} 
y encierra una situación clásica: el vendedor ambulante de enciclopedias que visita a una persona que se encuentra descansando en su casa y la convence de la necesidad de tener dicha enciclopedia en su hogar. El segundo ejemplo, derivado de los contratos celebrados a distancia, cuya regulación se encuentra en la directiva 97/7/CE, consiste en el caso de una persona que se encuentra trabajando en su oficina y recibe una llamada o un correo electrónico de una casa editorial que ofrece la suscripción a una revista en condiciones de difícil comprensión. En uno y otro caso nos encontramos ante una situación en la cual un operador comercial irrumpe en lugares de uso privado de un consumidor, que al momento se encuentra descansando o trabajando, concentrado en asuntos que nada tienen que ver con la intención de celebrar un contrato. Ese consumidor, se ve sorprendido jurídicamente por la irrupción del vendedor, así como por sus habilidades y las modernas y agresivas técnicas de comunicación y ventas, lo que lo conduce a aceptar la compra de un bien que en realidad no necesita o cuyas características en últimas desconoce, en contra de su propia y real voluntad.

A manera de conclusión, puede decirse que la individualización de la sorpresa como fenómeno proveniente de las relaciones contractuales, trae consigo la firme intención de identificar y hacer notorio el desequilibrio existente en dichas relaciones, las cuales se recuerda, son esencialmente llevadas a cabo por una parte que se encuentra, por naturaleza y circunstancias, en inferioridad de condiciones respecto de la otra.

\section{La sorpresa y el manejo de la información en general}

No cabe duda de que de la información y el manejo que se haga de ella son determinantes en la generación del fenómeno de la sorpresa, de manera que resulta útil analizar cómo dicha información se manifiesta dependiendo del nivel o de la forma en que es ofrecida al consumidor:

a. Falta de información: Se puede tratar seguramente del caso más común, y por ende, de aquel que produce mayor número de problemas. Genera la falta de preparación sicológica para concluir un contrato de parte del consumidor, que estando en su casa, o en su sitio de trabajo, se encuentra de frente a un inesperado vendedor, no siendo conciente, debido a que no tiene conocimiento del hecho, de la posibilidad de que un producto le sea ofrecido y por consiguiente, tampoco de los efectos de una eventual negociación. En efecto, la falta de información lleva consigo la imposibilidad de valoración, tanto del bien ofrecido como de las consecuencias jurídicas del contrato celebrado eventualmente. Esta situación es generada por el efecto sorpresa que se 
produce a su vez por el hecho de no conocer una circunstancia determinante dentro del proceso contractual.

b. Información errada: Se trata de una hipótesis que representa un grave efecto psicológico, dado que, mas allá de evitar la posibilidad al consumidor de ser consciente de una circunstancia que puede alterar su juicio sobre el contrato que eventualmente efectuará, lo obliga a realizar evaluaciones sobre una base errada. Inclusive esa valoración puede llevarse a cabo sobre realidades diversas, permaneciendo engañado sobre las verdaderas condiciones de contratación o sobre la calidad del producto. Un ejemplo claro puede ser la etiquetatura que no provee una veraz información sobre el respectivo producto (por cuanto relaciona el peso, los ingredientes, la calidad, entre otros) que producirá sin lugar a dudas, la sorpresa en la persona, al momento en que se presente la confrontación con la realidad, posiblemente modificando su juicio, en lo que se refiere a la compra de aquel determinado producto.

c. Exceso de información. El presente caso puede seguramente parecer paradójico, pero sin embargo constituye una grave fragmentación del circuito de la competencia que cada día toma mas fuerza y encuentra en el incorrecto uso de la publicidad comercial su ejemplo más usual y significativo. La publicidad comercial se presenta como un instrumento de enorme importancia para el correcto funcionamiento del mercado, dado que es fundamental al permitir ampliar la posibilidad de escogencia del sujeto económico interesado en adquirir el bien o servicio en cuestión, y acelera indudablemente la competencia:

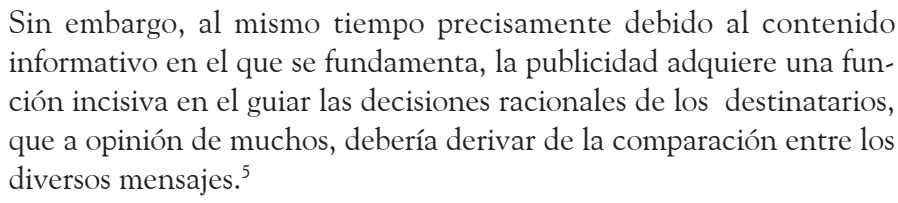

De esta manera, un consumidor puede ser sorprendido en relación a las verdaderas características de un producto o condiciones de un contrato, debido al indebido desarrollo de la publicidad, así como a su excesiva difusión, que terminan por crear una grave distorsión en el juicio del consumidor.

En conclusión, podría decirse que los problemas informativos conducen a la problemática contractual hacia un círculo vicioso concreto: tanto la falta de información, como el mal uso de ella dentro del proceso contractual, son elementos generadores de la falta de racionalidad dentro de la operación económica regulada por el contrato, que se manifiesta en la limitación de

${ }^{5}$ A. Jannarelli, Diritto Privato Europeo, Volume secondo, 1998, 527. 
la voluntad de uno de los contratantes, así como en la indebida formación del consentimiento. Dicha falta de racionalidad trae consigo un completo aislamiento de las operaciones contractuales individuales, lo que contribuye a su vez a que no exista un debido circuito informativo entre los procesos contractuales en general.

\section{La sorpresa y las asimetrías informativas}

La disparidad informativa es un factor diferente a los ya analizados, que merece, dada su influencia directa dentro del proceso contractual, un tratamiento particular sobre la base de su comportamiento dentro del mercado.

Por Asimetría Informativa se entiende la diversa y desigual disponibilidad de información que las partes intervinientes en un contrato tienen a su disposición.

Esta definición riñe con conceptos como el de mercado que en el ámbito de la literatura económica clásica, es un término "general y fundamentalmente asociado a la idea de la competencia por trazar un modelo de alguna manera ideal, en el que el equilibrio referente a la contratación se concretiza con el precio dependiendo del encuentro de la demanda y de la oferta" ${ }^{\text {toda vez que }}$ para que sea perfectamente competitivo:

[...] no basta que exista un gran número de adquirentes y de vendedores, es indispensable que cada uno de ellos sea informado de la presencia del otro...de modo que el mercado presupone fundamentalmente una plena transparencia en cuanto a la presencia de los diversos sujetos que son protagonistas y por consiguiente, exige la plena fluidez de la información de parte de cada uno ellos, sin que se tengan que soportar costos para obtenerla. ${ }^{?}$

Estas características contribuyen a que sea posible encontrar la concreta actuación y efectividad de la igualdad, y las mismas oportunidades que el mercado debe asegurar a todos sus protagonistas. No obstante, "no es suficiente que exista un circuito informativo que permita al contrayente informarse exclusivamente sobre la calidad del bien o servicio, es también necesario asegurar la presencia de un circuito análogo de información que observe la calidad del contrato, que depende por supuesto de las cláusulas contenidas

${ }^{6}$ A. Jannarelli, Diritto Privato Europeo, Volume secondo, 1998.

${ }^{7}$ Ibid. 
en cada contrato individualmente tomado". ${ }^{8}$ Solo así se asegura el carácter de comparables de las diversas ofertas, tanto con relación a la calidad de los productos como a la calidad de la disposición negocial proyectada.

La información asimétrica es entonces un enemigo no solo del correcto funcionamiento del mercado, también los es de la normal formación y del sano desarrollo del proceso contractual. Este tipo de falla en la información se manifiesta con relación a la calidad de los bienes y servicios ofrecidos, al precio de los mismos, a las características del contrato celebrado e incluso con respecto a las garantías legales ofrecidas al consumidor.

Es claro como la sorpresa es producto de la información asimétrica que se maneja en determinadas relaciones contractuales. La diferencia en la cantidad y calidad de información existente entre el operador comercial o vendedor y el consumidor, influye de manera directa, como ya se ha visto, en la voluntad de este último, así como en la formación del consentimiento y por ende, seguramente, en la existencia misma del contrato.

\section{5. ¿Qué se busca proteger a través de la normatividad que regula la sor- presa?}

Las normas que regulan el fenómeno de la sorpresa, así como las circunstancias de tipo social y económico que le sirven de soporte, no pueden entenderse como elementos aislados dentro del sistema jurídico de orden Comunitario. Tienen finalidades precisas y forman parte de un complejo grupo normativo con un sentido claro dentro del actual contexto jurídico europeo:

a. El primer objetivo que se ha trazado dicha normatividad es la estructuración eficiente del mercado para crear un ambiente idóneo en cuyo interior se pueda desarrollar correctamente la economía, así como las diversas relaciones jurídicas y sociales. Esta estructuración hace necesaria una serie de reglas "que asegure la correcta competencia en las negociaciones y que tenga la capacidad de remover los obstáculos y las imperfecciones que pueden emerger sobre el despliegue de la actividad negocial y, por consiguiente, a la más adecuada colocación de los recursos". 9

b. No obstante, "dentro de la disciplina contractual de origen comunitaria, la tutela del consumidor se revela en términos de medios más que de fines", ${ }^{10}$

${ }^{8}$ Ibid.

${ }^{9}$ N. Lipari Trattato di diritto europeo, III Tomo 2003.

${ }^{10}$ A. Jannarelli, Diritto Privato Europeo, Volume secondo, 1998. 
es innegable que un sistema de protección al consumidor encierra una enorme importancia en sí mismo, ya que asegura a quien actúa como adquirente no profesional, las condiciones necesarias para realizar elecciones económicojurídicas razonables, y le confiere la calidad de sujeto llamado a desarrollar un rol mucho más activo dentro de las relaciones jurídico económicas actuales.

c. En medio de su afán de regular el desarrollo tecnológico, así como la evolución de las relaciones humanas, la disciplina contractual europea ha creído conveniente proteger el proceso de formación del contrato y a los contratantes mismos de ciertas circunstancias a las que se ven expuestos debido a las características de las actuales formas de contratar. De esta forma, la normatividad sobre contratos celebrados fuera de local mercantil pretende fundamentalmente proteger al consumidor ante la vulnerabilidad psicologica en la que se encuentra al contratar, cuando se le ofrece un producto en un momento inoportuno. Con las normas que regulan la contratación a distancia, se protege igualmente al consumidor de las modernas técnicas de comunicación que impiden que se puedan llevar a cabo procesos de valoración física de los productos a adquirir. Con la normatividad de protección al consumidor en general (directivas No. 85/577/CE, 97/7/CE, 90/314/CEE, 94/47/CE, 98/6/CE y 99/44/CE) se le defiende de las actuales técnicas agresivas de venta que suelen distorsionar la capacidad de entendimiento de las personas.

\section{Soluciones y herramientas contra la sorpresa}

El legislador europeo ${ }^{11}$ a través de las directivas No. 85/577CE, 94/47/CE y $94 / 7 / \mathrm{CE}$, que tratan los temas de los contratos negociados fuera de establecimiento mercantil y los contratos celebrados a distancia respectivamente, ha ofrecido dos tipos de herramientas jurídicas a utilizar en contra de la sorpresa, la primera de carácter preventivo y la segunda de naturaleza restaurativa:

\section{a. Obligación de Información}

Esta medida pretende que el consumidor se encuentre informado respecto de las características generales que rodean el proceso contractual al que se

\footnotetext{
${ }^{11}$ El Consejo de la Unión Europea representa a los gobiernos de los Estados miembros, quienes en su seno legislan para la Unión, establecen sus objetivos políticos, coordinan sus políticas nacionales y resuelven las diferencias existentes entre ellos y con otras instituciones. La Comisión Europea, es una institución políticamente independiente que representa y defiende los intereses de la Unión Europea en su conjunto, propone la legislación, políticas y programas de acción y es responsable de aplicar las decisiones del Parlamento Europeo y el Consejo de la Unión Europea.
} 
enfrenta de improviso, a través de una obligación impuesta al operador comercial. Las materias sobre las cuales recae esta obligación pueden sintetizarse en las siguientes:

- Información general sobre el productor o distribuidor del producto, que busca que el consumidor tenga plena identificación de la persona con quien contrata.

- Información acerca de las características del bien o servicio ofrecido. El operador comercial debe identificar plenamente las condiciones y atributos del producto y hacer total claridad en cuanto a que las funciones y condiciones del mismo sirven o son afines a su naturaleza.

- Información acerca del precio. El consumidor debe estar muy bien informado acerca del valor total del bien o servicio, así como de las variaciones que el precio pueda sufrir dependiendo de que se presenten variables en el negocio.

- Información sobre las acciones judiciales y pre-judiciales existentes, en cabeza del consumidor. Fundamentalmente del derecho de revocación, como se verá a continuación.

En cuanto a este deber en cabeza del empresario u operador comercial, es posible afirmar que trae consigo un importante efecto con relación a la disciplina contractual de protección al consumidor: nos encontramos ante un contrato claramente formalista. De un lado, la necesidad de información de la relación contractual y la manera en que debe ser comunicada impiden que el acto jurídico se pueda llevar a cabo de manera verbal y, consecuentemente, el desarrollo y ejecución del contrato mismo, que "debe contener una serie de elementos explicativos del contenido de la prestaciones que de el se deducen", ${ }^{12}$ se ven limitadas por una serie nutrida de reglas.

\section{b. Derecho de revocación}

Es también llamado derecho a reconsiderar. Consiste en la posibilidad que tiene el consumidor de replantearse la necesidad de llevar a cabo la operación contractual. Es utilizado por el consumidor en los casos en los que no se encuentra a satisfacción son las características del bien o servicio objeto del contrato, con la particularidad de que el consumidor no debe especificar el motivo que lo lleva a tomar tal determinación, ni se expone a penalidad alguna. 
La revocación en este caso, acompaña los contratos que "por el particular contexto físico-técnico de la comunicación entre las partes generan el riesgo de que el consumidor sufra el efecto sorpresa, y justamente para neutralizar este riesgo, se le atribuye la facultad de reconsiderar, de cambiar de idea y de salir del contrato que ya se ha perfeccionado". ${ }^{13}$

Este derecho se ejercita dentro de un tiempo determinado, que generalmente son 7 días contados a partir del momento en que el consumidor tuvo a su disposición el producto objeto del contrato. Sus efectos son los siguientes:

- La restitución del producto de parte del consumidor.

- La restitución de parte del operador comercial del dinero pagado, de manera gratuita y en el menor tiempo posible.

- La disolución del vínculo contractual, quedando las partes exoneradas de cualquier obligación derivada del mismo.

- Las partes adquieren la posición jurídica y económica que tenía antes de iniciar el proceso contractual.

Esta última herramienta, sin duda útil para combatir el efecto sorpresa y presente en gran parte de la disciplina de los contratos del consumidor, ${ }^{14}$ trae consigo una serie de efectos sobre los cuales vale la pena reflexionar:

- Encierra evidentes ventajas como la rapidez de los procedimientos a través de los cuales se lleva a cabo, la ausencia del mecanismo judicial y la posibilidad de que las partes puedan iniciar nuevas operaciones jurídico-económicas en óptimas condiciones.

- Es cierto también que trae consigo inconvenientes que se derivan de su inadecuado uso. Es claro que en un momento determinado, el consumidor injustificadamente insatisfecho puede abusar de la figura y acarrear inconvenientes desmedidos a los vendedores y operadores comerciales, toda vez que "relaciona la disolución del vínculo con la mera reconsideración subjetiva, al límite caprichoso de una de las partes". ${ }^{15}$

\footnotetext{
${ }^{13}$ V. Roppo, Il contratto e le Tutele, Página 85, Giappichelli, 2002

${ }^{14}$ Contratos celebrados fuera de establecimiento mercantil, contratos celebrados a distancia, contratos de venta de productos financieros ofrecidos con técnicas de comunicación a distancia, contratos de multipropiedad.

${ }^{15}$ V. Roppo. Il contratto e le Tutele, Página 85, Giappichelli, 2002
} 
- El hecho en sí de poder disolver el vínculo contractual de una manera sencilla y definitiva es de resaltar, independientemente de los efectos positivos o negativos que esto pueda acarrear. La cesación de las obligaciones para ambas partes, al igual que la devolución de las prestaciones ya ejecutadas en las condiciones planteadas, constituyen un cambio drástico con respecto a la disciplina contractual tradicional.

- El punto anterior conduce necesariamente a pensar que en los contratos de protección al consumidor la voluntad individual, fundamentalmente la de una de las partes, prima en detrimento del consentimiento. La unilateralidad adquiere una enorme libertad en aras de la obtención del equilibrio económico del contrato.

- Es claro entonces que para con el vínculo contractual "la nueva disciplina de los contratos del consumidor lanzan un gran desafío"16 a través del derecho a reconsiderar: se fractura el principio a través del cual el contrato se encuentra dotado de fuerza de ley entre las partes, que pretende precisamente que los contratantes estén imposibilitado de evadir sus obligaciones de manera unilateral.

- Más allá de las naturales críticas que puedan surgir en general, es del todo rescatable la intención de la Unión Europea, de procurar equilibrio y bienestar a las relaciones contractuales entre comerciantes y consumidores, adecuándolas a las actuales formas de relación jurídica.

- Es igualmente positivo que la nueva disciplina contractual de la unión pretenda que cada contrato, tomado de manera individual, se pueda insertar en un correcto circuito de competencia que impida el aislamiento de las distintas relaciones jurídico económicas.

\section{Los contratos negociados fuera de establecimientos mercantiles como base de la sub especie}

Los contratos negociados fuera de establecimiento mercantil pueden considerarse como la base del fenómeno de la sorpresa, dado que fueron los primeros,

${ }^{16}$ V. Roppo, Il Contratto e le Tutele, Página 89, Giappichelli, 2002 
desde el punto de vista cronológico, en desarrollarse y por ende, en producir efectos a nivel general en relación con la sorpresa como fenómeno capaz de determinar el desarrollo de una operación económico jurídica. Han sido, en consecuencia, los primeros en ser regulados por la normatividad europea, así como por las normativas particulares de cada estado miembro.

De hecho, debido a que son contratos necesariamente ligados a las modernas técnicas de venta, aunque algunas ya son considerados elementales o comunes (contratos a domicilio), se puede afirmar que han representado el inicio del grandísimo desarrollo tecnológico que han llevado consigo las nuevas relaciones contractuales (contratos telemáticos), acompañados a veces, de un alto nivel de complejidad, ya sea en el plano jurídico social como en el económico.

En consecuencia, estos contratos se presentan como la primera forma verdaderamente moderna de producir ciertos efectos sobre las partes, sin que exista necesariamente consciencia de esto en una de las mismas, y al mismo tiempo, como la oportunidad para el legislador de adquirir conciencia sobre la necesidad de una normatividad que la regule.

En conclusión, la norma reguladora de los contratos negociados fuera de establecimiento mercantil constituye el primer tentativo de entender la relación existente entre tecnología y derecho, así como las nuevas formas de concebir la realidad y las instituciones jurídicas.

\section{Análisis del tipo contractual (Directiva 85/577)}

La Unión Europea ha regulado el tema mediante la Directiva 85/577, que ha sido por supuesto aplicada a los respectivos países de la Unión a través de su respectiva normatividad. Para el caso en mención, se ha tomado la aplicación realizada por el legislador italiano, llevada a cabo por medio del Decreto Legislativo No. 50 de 1992, para exponer en qué consiste el tipo contractual, cuáles son sus características y de qué manera regula el fenómeno de la sorpresa.

a. Sujetos:

- Consumidor: Debe ser una persona física, y al momento de efectuar la operación económica no puede tener un interés a nivel profesional. Es relevante decir que las amas de casa sean o no consideradas como profesionales, se encuentran tuteladas por el Decreto lgs 50/92. 
- Operador Comercial: De conformidad con la intención del legislador, será aquel (persona física o jurídica), que al momento de efectuar la operación económica actúe en el ámbito de su actividad profesional.

Se deben incluir igualmente las personas que actúan a nombre o por cuenta del operador comercial, así como todos aquellos que participan en el ciclo económico como intermediarios.

b. Ámbito de aplicación objetivo:

La condición esencial para aplicar la normatividad en estudio es que entre un operador comercial y un consumidor se desarrolle un contrato o propuesta contractual en cualquier modalidad, sea vinculante, no vinculante, relacionada con el suministro de bienes o la prestación de cualquier tipo de servicio, siempre que se presenten las siguientes circunstancias:

1. Casos de venta puerta a puerta. En este caso, es determinante el lugar donde se puede encontrar al consumidor al momento de recibir la visita del operador comercial (art 1, comma 1 del D. lgs 50/92) toda vez que el primero no se encuentra en un lugar donde quiera espere o intente adquirir un bien o servicio, no estando preparado para actuar razonablemente en el contexto de la concreta operación económica. Es el caso de la persona que, encontrándose trabajando o realizando quehaceres domésticos no está preparada para celebrar un contrato ni para prever las consecuencia provenientes del mismo.

Es importante anotar, el hecho de que, en este caso, el legislador italiano, de acuerdo al contenido del artículo 8 de la directiva 85/577 CEE (según la cual cada Estado miembro puede ampliar la tutela al consumidor) ha determinado que la tutela se presente incluso cuando la visita del operador comercial pueda provenir de la iniciativa del consumidor mismo, circunstancia no contemplada en la directiva original.

2. Excursiones organizadas fuera del establecimiento mercantil. El legislador buscar tutelar aquellos eventos en que el operador comercial (con objeto marketing) organiza actividades recreativas en lugares diversos de la sede de la empresa, en el curso de las cuales efectúa las propias propuestas comerciales.

Partiendo de la dificultad que puede encontrar el intérprete con la determinación del alcance del término establecimiento mercantil, se podría decir que el criterio a analizar para determinar el verdadero alcance de la tutela en este 
caso particular es si el operador comercial, durante la excursión, desarrolla una actividad de mera estimulación al consumo o presta en realidad un verdadero servicio de información al consumidor.

En el primer caso, la tutela se presentaría de manera clara, visto el peligro al que se encuentra expuesto el consumidor, de no saber si en realidad el bien ofrecido es deseado o no, con el agravante de encontrarse en un entorno especialmente gestado y concebido por parte del vendedor u operador comercial para generar en él un grado superior de impresión sobre el bien ofrecido; en el segundo caso, por lo contrario, sería totalmente injustificada la tutela. ${ }^{17}$

Como se verá después, se tutelan no solamente los contratos concluidos en estas circunstancias, sino aquellos que han sido efectuados solamente fuera de locales comerciales.

3. En área pública o abierta al público. Se debe pensar en aquellas personas que ejercitan la actividad comercial en lugares de diversa naturaleza, como stands, bancas, cubículos, y en general lugares de diversa naturaleza.

4. Correspondencia o trámite medios audiovisuales, informáticos o telemáticos (art 1 d), art 9 D.lgs 50/92). Con estos, el legislador ha querido regular de igual forma los casos en que no existe contacto físico entre las partes.

Cuando la normativa se refiere a los contratos por correspondencia, abarca varias modalidades como las cartas, anuncios, periódicos, catálogos, videocasetes, teléfono, etc., sin que exista relevancia sobre la manera en que los mismos llegan al consumidor.

Las ventas a través de televisión u otros medios audiovisuales son temas que están relacionados con la disciplina mas concreta de los contratos negociados a distancia, regulados por la directiva 97/7/CE recibida por el legislador italiano mediante el decreto legislativo N. 185/99, que en su artículo 15 dispone que, pudiendo existir "coincidencia" normativa entre este y el decreto 50/92, se dará aplicación a las disposiciones mas favorables para el consumidor contenidas en el primero.

El decreto legislativo N. 185/99, indica con claridad que su aplicación depende del hecho de que el proveedor emplee durante la totalidad del proceso

${ }^{17}$ Caringella, pág 2270. 
de contratación, incluyendo el acto de conclusión mismo, una o varias técnicas de comunicación a distancia (art 1, a).

Una consideración particular debe ser dirigida al hecho de que el legislador Europeo ha querido equiparar al contrato las propuestas contractuales hechas por el consumidor (sean o no vinculantes, y en las cuales no exista aceptación del operador comercial), dándole los mismos efectos jurídicos. En realidad, lo único que ha hecho el citado decreto es indicar que los efectos propios de la norma analizada se aplican independientemente de la forma que asuma la voluntad del consumidor, al momento de una negociación efectuada fuera de locales comerciales. ${ }^{18}$

Con la situación anteriormente descrita se pretende regular la denominada "contratación standard", dado que en realidad tal propuesta no proviene del consumidor, mas si del operador comercial quien de manera anticipada ha proyectado y planeado todo el proceso contractual que hace ver al consumidor como el sujeto que tiene la iniciativa contractual.

\section{El derecho a "reconsiderar"}

La verdadera innovación que trae consigo la disciplina de los contratos negociados fuera de establecimientos mercantiles es el "instrumento" que el legislador europeo pone al servicio del consumidor: el derecho de revocación. El instrumento tiene un concepto claramente definido por la legislación de la Unión, e incluye elementos determinantes como el nivel de información que debe presentar el proceso negocial y las diferentes modalidades mediante las cuales se manifiesta, así:

\section{a. Concepto (art 4 )}

Consiste en el derecho que tiene el consumidor de replantearse la necesidad de llevar a cabo la operación contractual elegida. Lo anterior tiene como sustento que los modernos sistemas de ventas agresivas donde la iniciativa proviene generalmente del operador comercial tienen procesos de negociación, e inclusive de contratación ya predispuestos, que influencian directamente la voluntad del consumidor y su capacidad de razonar y darse cuenta de si su elección de celebrar un contrato, en unos casos o la relativa al objeto del mismo en otros, ha sido correcta o por el contrario guiada e inducida por el operador comercial.

${ }^{18}$ Canale, 1992, pag 184 
En consecuencia, el derecho de revocación dentro de la disciplina que aquí se comenta ofrece al consumidor la posibilidad de repensar si su escogencia ha sido razonada, y consciente, y por consiguiente, permite la disolución del contrato (cuando ha sido perfeccionado) o la interrupción del proceso de formación del mismo.

En relación con este tema, vale la pena preguntarse si podría el operador comercial ejercer el derecho de revocación de la misma manera en que lo hace el consumidor. $\mathrm{Al}$ respecto, nada dice la norma europea que pudiera impedir al operador comercial el ejercicio de dicho derecho, siempre que no constituya un abuso contra el consumidor. La pregunta entonces sería: iqué objeto habría en la posibilidad de repensar sobre la racionalidad de la operación económica, en la persona en que se presenta la ventaja informativa y la adecuada preparación psicológica para ejecutar la prestación?

\section{b. Información (art. 5)}

La legislación europea impone al operador comercial la obligación de informara al consumidor de la existencia del derecho de revocación, así como de sus términos, modalidades y eventuales condiciones para su ejercicio. Esta obligación varia en cada uno de los países de la Unión Europea, creando una gran variedad en la manera de informar dentro de la Unión.

En el caso italiano, el cual se ha tomado como parámetro, el legislador ha querido que esta obligación fuera especialmente reforzada, razón por la cual el operador comercial deberá suministrar al consumidor todas las indicaciones del sujeto frente al cual ejercita el derecho de revocación como su dirección y si se trata de persona jurídica la denominación o sede de la misma. En cada caso el derecho de revocación no iría sujeto a ningún término o modalidad.

Dentro del tema de la información, es importante anotar que esta puede ser suministrada en dos momentos:

- Al momento de la estipulación del contrato

- Al momento del acto de formulación de la propuesta.

Adicionalmente, se deben indicar el lugar y la fecha en que se efectuará la entrega al consumidor, así como los elementos necesarios que permitan identificar la naturaleza del contrato. Con esto, el legislador ha querido que el intérprete pueda identificar de manera calara y sencilla que se trata de un contrato negociado fuera de establecimientos mercantiles con todos sus efectos, independientemente de la forma o denominación que adopte. 
Por seguridad, y con fines probatorios, desde el momento que indica la información, el operador comercial puede pedir un copia suscrita por él (demostrando el cumplimiento de su obligación).

Una última consideración amerita el caso italiano, en donde el legislador no impone la forma escrita en el contrato (ad substantiam), pero si lo hace respecto de la obligación de información sobre el derecho de revocación. La razón podría ser que, en un eventual incumplimiento, donde la forma escrita del contrato es obligatoria, podría generar la nulidad del contrato, lo que en última penalizaría al consumidor.

Sin embargo, si bien no existe norma expresa que así lo indique, del contexto del D. lgs 50/92 (y más que nada de las normas establecidas en el código civil Italiano, art. 2721 ss) se puede entender la obligación de la forma escrita (ad probationem) en el contrato negociado fuera de locales comerciales. De esta manera, quedaría en este sentido la duda sobre la coherencia de una disciplina que no prescribe la forma escrita para que el acto sea válido (art.1350cc), y que en cambio lo hace para la obligación de información sobre el derecho de revocación, de cuyo cumplimiento depende el contrato mismo. ¿Existe la exigencia entonces de un requisito de forma escrita para un acto cuya base puede ser oral? Al respecto, ise informaría sobre el derecho de revocación si las partes no han escogido la forma escrita del contrato? Ante Todas estas dudas, podría decirse que esta se puede entender como una disciplina práctica que busca introducir instrumentos de tutela "adicionales", respecto de aquellas ya previstas en la tradición de los diferentes códigos civiles, sin que se limiten o excluyan recíprocamente, con la finalidad de que la operación económica alcance sus efectos, y por consiguiente, cumpla con la tarea de que el consumidor tenga la posibilidad de repensar si su escogencia ha sido o no razonable, sobre la base de la conciencia de los derechos de que goza, así como de las formas en que estos deben ejercitarse.

Finalmente, se puede agregar que si se estableciera la obligación de la forma escrita (ad substatiam) en el contrato, esta tendría como consecuencia en caso de incumplimiento, la nulidad (art 1325, n. 4 c.c. - art 1418 , comma 2 c.c.), que con sus efectos (art. 1421 - art 1423 c.c.) podría también penalizar al consumidor desfavoreciéndolo en muchos casos, situación que no sería lógica dentro de una disciplina cuya finalidad es precísamente la de protegerlo. 
c. Modalidad (art 6).

\section{Tutela}

Existen dos tipos de tutela, dependiendo de que el consumidor sea informado o no sobre el derecho de revocación:

Existe información (7 dias):

- Contratos que tienen por objeto la prestación de servicios: a partir del momento de la suscripción o de la nota de, siempre que el producto o servicio sea exhibido por el operador comercial.

- Ventas sobre la base de catálogos o sin la presencia del operador comercial: a partir de la fecha de recepción de la mercancía.

- Cuando se muestra un producto diverso de aquel estipulado en el contrato: a partir de la recepción de la mercancía.

Cuando la información no ha sido suministrada por el operador comercial, o cuando ha sido suministrada de manera incompleta o inexacta (En este caso se otorgarán sesenta días).

Es importante determinar que el error en la información debe ser de aquellos que no permitan al consumidor el normal ejercicio del derecho de revocación. Esto, no obstante, no quiere decir que el consumidor se encuentre exonerado de su obligación de exigencia media.

Los sesenta días deben transcurrir a partir de:

- La fecha de la recepción, en caso de suministro de mercancías.

- La fecha de la estipulación del contrato, en el caso de contratos de prestación de servicios.

Resulta importante recordar que, dado que en Italia, y en otros paises europeos, las normas sobre el derecho de revocación unilateralmente tienen un carácter dispositivo, se podría derogar, si las partes lo desean, pactando cláusulas de mayor tutela para el consumidor, o para la operación económica en general. ${ }^{19}$ No obstante lo anterior, para una mayor comprensión de la revocación dentro de los contratos negociados fuera de establecimiento mercantil, se debe tener en cuenta la forma como se ejercita, las condiciones del ejercicio y sus efectos, así:

${ }^{19}$ P. Putti, Diritto Privato Europeo, Volume secondo, 1998, pag 215. 


\section{Ejercicio (art. 6)}

El ejercicio del derecho de revocación se puede efectuar en dos formas diversas:

- A través de correo certificado: El consumidor que entiende ejercitar el derecho de revocación debe enviar al operador comercial una comunicación en tal sentido, mediante correo certificado con el respectivo comprobante de recibo.

- A través de la simple restitución del bien: En los casos en que son usadas las denominadas cláusulas "satisfechas o rembolsadas", aplicadas al género de los contratos cuya base son los catálogos o por correspondencia, no existe la obligación de parte del consumidor de especificar que se entiende que ejercita el derecho de revocación y la posterior restitución de la mercancía. Simplemente se debe efectuar la restitución dentro del término previsto, aunque en realidad no se aclara la forma en que la misma se deba hacer.

En lo que se refiere a la ejecución del derecho de revocación, en general se concluye lo siguiente:

- Para ejercitar el derecho de revocación solo basta tener la capacidad para ello. Esto lleva a tres conclusiones: (i) El derecho de revocación puede ejercitarse a través de representante, (ii) Si el derecho de revocación lo ejercita una persona incapaz, el acto con el cual se ejercita el derecho sería nulo, y (iii) En el caso en que el contrato sea suscrito por una parte compuesta por varios sujetos el derecho de revocación no podrá ser ejercitado singularmente, salvo que las partes hayan pactado alguna cosa en contrario.

- Finalmente, será de utilidad, para los fines de un óptimo ejercicio del derecho de revocación, diferenciar entre el intermediario (agente) y el operador comercial o el productor (revendedor autorizado, representante, etc.) ya que solo frente a este último se puede ejercitar eficazmente.

\section{Condiciones (art 7)}

El ejercicio del derecho de revocación debe respetar unas condiciones mínimas para producir sus efectos, respetando de esta manera a la contraparte, y evitando abusos de parte del consumidor. La condición esencial para el ejercicio 
del derecho de revocación será la restitución de las mercancías al operador comercial. Existirán diversos tipos de restitución que dependen a su vez del tipo de contrato, así como la modalidad de información del mismo.

1. Contratos que tienen por objeto la venta de bienes: En este caso es útil distinguir dos situaciones que se presentan: a) El operador ha informado al consumidor de la existencia del derecho de revocación, sus términos, modalidad, etc. La interpretación de la norma en este punto en particular no es clara, sin embrago de acuerdo a la naturaleza de la subespecie, y teniendo en cuenta que existe consciencia sobre la existencia del derecho de revocación y sus características, se podría decir que antes de restituir el bien, el consumidor podrá manipularlo solamente en el tiempo y en las condiciones que sean necesarias para darse cuenta de las condiciones materiales del bien, y por consiguiente, del motivo que lo lleva a ejercitar el derecho de revocación sin dejar rastros sobre su uso, ${ }^{20} \mathrm{y}$ b) Cuando el operador haya omitido suministrar al consumidor la información sobre el derecho de revocación, así como los términos de este, la modalidad, etc. Lo anterior lleva a la consecuente extensión del término para el ejercicio del derecho a sesenta días, tiempo suficiente para que la mercancía sea restituida en normal estado de conservación, en cuanto haya estado custodiada y eventualmente manipulada con el uso de la normal diligencia, dado que el consumidor no es consciente de la facultad de disolver el vínculo contractual. ${ }^{21}$

2. Contratos relativos a prestación de servicios: en este caso, el derecho de revocación opera solamente ex nunc, sin incidir sobre las prestaciones ejecutadas. Sobre este argumento se pueden presentar inconvenientes que serán tratados en el próximo punto.

\section{Efectos (art 8)}

Con el correcto uso del derecho de revocación el legislador desea que las partes tornen a la posición económica y jurídica en la que se encontraban inicialmente, es decir, antes de concluir el contrato o la operación económica misma. En consecuencia, se deben entender disueltas las obligaciones futuras, debiendo de igual forma restituir las prestaciones ya recibidas, de ser este el caso. En tal sentido, es necesario diferencias los siguientes eventos:

${ }^{21}$ Caringella ,pag 2276 
1. No han sido cumplidas las obligaciones: en este caso, se entenderá que el vínculo contractual se disuelve, y las partes se encuentran exoneradas de cualquier obligación derivada del mismo, o de la propuesta contractual, siempre que el operador comercial haya recibido la comunicación enviada por el consumidor.

2. Las obligaciones han sido cumplidas de manera parcial: las partes deben proceder a las restituciones mutuas. El consumidor debe restituir la mercancía recibida dentro de los siete días siguientes a la entrega, soportando a su cargo los gastos de expedición, y el operador a su vez debe rembolsar al consumidor las sumas pagadas por éste, dentro de los treinta días siguientes.

3. Contratos que tienen por objeto la prestación de servicios: en este caso la restitución que efectúa el operador estará limitada a las sumas pagada por el consumidor, debiendo descontar el pago correspondiente a las prestaciones efectuadas.

Al respecto, se observa que en este tipo de sistema, podrían atenuarse significativamente los efectos prácticos del derecho de revocación, siendo hipotéticamente mas favorable para el consumidor el art. 2041 del CC Italiano, que establece el pago de una indemnización en el caso en que pueda probarse un enriquecimiento. ${ }^{22}$ Por ultimo, es importante tener en cuenta que el derecho de revocación tiene como característica fundamental su irrenunciabilidad, la cual genera algunas consideraciones generales:

\section{Irrenunciabilidad (art 10)}

El D.lgs 50/92 es claro al establecer que el derecho de revocación es irrenunciable, y que será nulo todo pacto que contravenga esto.

Con esta norma imperativa e inderogable, el legislador buscar fijar los requisitos mínimos que conllevan a la igualdad sustancial entre sujetos económicos, que llevará a la operación comercial las condiciones ideales para producir sus correspondientes efectos económicos.

De este modo, surge la pregunta de si en ausencia de norma expresa la nulidad de los pactos contrastantes con el D. Lgs (por cuanto no existe una cláusula que informe sobre el derecho de revocación, o existiendo, es lagunosa o condicionada ilegítimamente), puedan extenderse a la totalidad del contrato.

${ }^{22}$ F. Astone, 1992, pag 224 
La respuesta, tal y como ha sido aceptada generalmente por la doctrina, debería ser negativa, dado que la finalidad esencial del contrato es la producción de efectos económicos, situación que solo podrá lograrse si sobrevive, manteniendo la totalidad de sus características.

Se debería entonces proceder a una declaración de nulidad parcial, y a una integración de las partes nulas del contrato, mediante la sustitución de las mismas bajo los parámetros de la disciplina legislativa.

\section{Consideraciones generales}

En cuanto se refiere a los efectos del derecho de revocación, es importante tener en cuenta las siguientes consideraciones de carácter general:

- Como se ha dicho hasta este momento, en lo que se refiere a la disciplina de los contratos negociados fuera de establecimientos mercantiles, así como a los efectos del derecho de revocación, el D. Lgs 50/92 equipara el contrato a la propuesta contractual y sus consecuencias resultan ser en ambos casos la disolución de la relación económico y la inexistencia de fuente de obligaciones a partir de la propuesta. Lo anterior, seguramente debido a que el legislador ha querido una disciplina simple dotada de remedios de uso fácil y práctico, no obstante se alejen un poco de los conceptos y valores de la tradición contractual europea.

- Por la misma razón, el ejercicio del derecho de revocación en esta disciplina es de naturaleza fundamentalmente gratuita, limitándose a poner a cargo del consumidor, únicamente los gastos de expedición para la restitución de la mercancía recibida, así como los eventuales pactos de carácter accesorio. ${ }^{23}$

- Si bien la normatividad nada diga sobre el argumento, con la finalidad de proteger la situación económica de ambas partes, al momento de efectuar la restitución de la mercancía, el consumidor deberá ser responsable por los daños causados al bien por hechos propios, al límite de su enriquecimiento (arts 2041-2037cc) y por el incumplimiento (art1228 cc) si lo realiza a través del servicio postal.

- Igualmente, en el caso de incumplimiento del consumidor de la obligación de restituir el bien, el operador podrá incoar la acción por incum-

\footnotetext{
${ }^{23}$ Caringella, pag 2276.
} 
plimiento (art. 1640 cc) y "refutar" la obligación de rembolsar las sumas pagadas, dado que la obligación de restitución derivada de la disolución del contrato de prestaciones "correspondientes", es de la misma manera "correspondiente". ${ }^{24}$

- Las últimas dos consideraciones encuentran su razón, desde una óptica general, en la que la revocación, si bien es una importante oportunidad que tiene el consumidor para "reconsiderar" sobre la elección efectuada, no puede convertirse en un instrumento que permita al consumidor cometer los mismos abusos que teóricamente busca evitar.

\section{Conclusiones}

1. La disciplina de los contratos del consumidor se estructura sobre la base de éste como realidad económica actual que no representa al individuo como tal, o las formas individuales de negociar y de perfeccionar un contrato, sino mas bien a una categoría de sujetos económicos general y anónima que llevan a cabo una elección de una serie de bienes ofrecidos en masa.

2. La política de protección al consumidor no debe fundamentarse sobre la base de la figura del consumidor mismo como parte débil de la relación contractual. Es la necesidad de una relación contractual equitativa que esté en capacidad de permitir al contrato como operación económica producir sus efectos, la razón que estructura dicha política.

3. El derecho de revocación como posibilidad de "replantear" por parte del consumidor una determinada actuación contractual tiene como objetivo claro el reequilibrar una relación jurídica perjudicada por elementos externos como las asimetrías informativas, para lograr que las partes cumplan con sus fines económicos y estén en capacidad de llevar a cabo nuevas operaciones económicas.

4. La sorpresa actúa como fenómeno con consecuencias jurídicas en la medida en que afecte la capacidad volitiva y racional de uno de los contratantes, logrando con esto influenciar negativamente el proceso formativo de una operación contractual determinada. 


\section{AUTORES DE LOS ARTÍCULOS}

\section{Alejandro Aponte}

Abogado de la Universidad Externado de Colombia. Doctor en Derecho Penal y Filosofía del Derecho de la Universidad de Saarland. Consultor del Consejo Superior de la Judicatura y de la Escuela Judicial.

\section{Daniel Bonilla}

Abogado de la Universidad de los Andes. Maestría y doctorado en Derecho en la Universidad de Yale. Profesor asociado en la Facultad de Derecho de la Universidad de los Andes, Bogotá.

\section{Mario Cajas}

Abogado de la Universidad del Cauca, Especialista en derecho público de la Universidad Externado, Maestría en Derecho de la Universidad Nacional de Colombia. Profesor de derecho constitucional y director del programa de Derecho de la Universidad Icesi.

\section{Federico Escobar}

Graduado en Literatura Inglesa en la Universidad de Tulane. Abogado de la Universidad Icesi. Profesor en la Universidad Icesi.

\section{Lelio Fernández}

Profesor y decano de la Facultad de Derecho y Ciencias Sociales de la Universidad Icesi.

\section{Fernando Gandini}

Abogado de la Universidad San Buenaventura, de Cali. Magister en Derecho de la Universidad de Roma. Profesor de derecho privado en la Universidad Icesi. Abogado Asesor.

\section{Alejandro Martín}

Matemático de la Universidad de los Andes, estudios de postgrado en Filosofía. Profesor de Matemáticas y de Lógica en la Universidad Nacional de Colombia y en la Universidad de los Andes.

\section{Bernhard Schlink}

Estudió Derecho en Heidelberg y en la Universidad Libre de Berlín. Doctorado en Derecho en Heidelberg. Profesor de derecho público y de filosofía del derecho en la Universidad Humboldt de Berlín. Juez en la Corte Constitucional del Estado federal Nordrhein-Westfalen en Münster. Novelista.

\section{Vittorio Villa}

Profesor de filosofía del derecho en la Facultad de Jurisprudencia de la Universidad de Palermo, Italia. Miembro del comité directivo de la Sociedad italiana de Filosofía analítica. 


\section{INDICACIONES PARA TRABAJOS DESTINADOS A PRECEDENTE}

1. PRECEDENTE tendrá en cuenta la clasificación de documentos propia de Colciencias para aplicarla a escritos en el campo del derecho o afines a él:

a) Artículos de investigación científica: documentos que presentan resultados derivados de proyectos de investigación científica. Los procesos de los que se derivan están explícitamente señalados en documento y el resultado satisface el examen hecho por árbitros.

b) Artículos de reflexiones originales sobre un problema o tópico particular: documentos que corresponden a resultados de estudios sobre un problema teórico o práctico, que al igual que los anteriores, satisfacen las normas de certificación sobre la originalidad y calidad por árbitros anónimos calificados.

c) Artículos de revisión: estudios hechos con el fin de dar una perspectiva general del estado de un dominio específico de la ciencia y la tecnología, de sus evoluciones durante un período de tiempo, y donde se señalan las perspectivas de su desarrollo y de evolución futura. Estos artículos son realizados por quienes han logrado tener una mirada de conjunto del dominio y están caracterizados por revisar una amplia bibliografía, que se refleja en el gran número de referencias bibliográficas.

d) Notas: documentos cortos que tratan sobre un tópico específico del dominio cubierto por la revista.

e) Comunicaciones (letters): documentos que son más cortos que un artículo normal, usualmente con un número menor de referencias, que pueden dar cuenta de resultados originales de investigación o de otros estudios.

f) Ponencias (Proceedings): trabajos ya presentados en eventos académicos - congresos, coloquios, simposios - que no han sido objeto de un proceso de certificación pero que, en general, son consideradas por el editor contribuciones originales y actuales en el dominio de publicación de la revista.

2. Los documentos pueden ser solicitados por esta publicación a personas invitadas a colaborar, o pueden ser enviados espontáneamente. En todo caso, la publicación someterá a evaluación de árbitros los escritos y se reserva el derecho de aceptarlos para la publicación o de no aceptarlos.

3. Los documentos enviados deben ser totalmente inéditos y quien los envía debe confirmarlo por escrito.

4. Los documentos comprendidos por los literales $a, b, c$ y $f$ deben ser acompañados por un breve resumen de no más de ochenta palabras -en Español y en Inglés-, por una concisa hoja de vida de la autora o autor y por el dato correspondiente sobre la clasificación de Colciencias.

5. Los documentos deben estar escritos en fuente $\mathrm{N} N 12$ y con interlineado 1.5. Deben ser enviados en copia impresa, acompañada por disquete en Word Win o compatible con IBM.

6. No se devolverán los documentos que el Comité editorial decida no publicar. 
